\title{
Chapter 4: Big data optimization in electric power systems: A review
}

Author(s):

I. Rahimi (Islamic Azad University, Isfahan, Iran, iman83@gmail.com)

*A. Ahmadi ( University of New South Wales, UK, ahmadi.abdollah.janah@gmail.com)

A. F. Zobaa (Brunel University London, UK, azobaa@ieee.org)

A. Emrouznejad (Aston Business School, UK, A.Emrouznejad@aston.ac.uk)

S.H.E. Abdel Aleem (15th of May Higher Institute of Engineering, Egypt, engyshady@ieee.org)

\subsection{Introduction}

There are different definitions of big data, and among them, the most common definition refers to three or five characteristics, called volume, velocity, variety, value, and veracity from (Laney (2001)). Volume could include Tera Byte, Peta Byte, Exa Byte, and Zetta Byte. Velocity describes how fast the data are retrieved and processed "Batch or streaming”. Variety describes structured, semi-structured, and unstructured data (Laney, 2001, Zikopoulos and Eaton, 2011). Veracity explains the integrity and disorderliness of data, while value refers to how good is the “value” we derive from analyzing data? (Zicari et al., 2016).

Electrical power systems are networks of components arrayed to supply, transfer, and use electric power. In power system since models are used to predict and characterize operations. However, there is a necessity for powerful optimization algorithms for information processing to learn models as the size increase of data is becoming a global problem to solve large-scale optimization problems. Any optimization problem includes a real function to be maximized or minimized by systematically determination of input values from an allowed set of values. Richness and quantity of large data sets provide the potential to enhance statistical learning performance but require smart models that use the latent low-dimensional structure for effective 
data separation.

This chapter reviews the most recent scientific articles related to large and big data optimization in power systems. Optimization issues such as logistics in power systems and techniques including nonsmooth, nonconvex, and unconstrained large-scale optimization are presented. After a brief review of big data, scientometric analysis has been applied using keywords of "big data” and “power system.” Besides, keywords analysis, network visualization, journal map, and bibliographic coupling analysis have been done to draw a path on big data works in power system problems. Also, the most common useful techniques in large-scale optimization in power system have been reviewed. At the end of this chapter, metaheuristic techniques in big data optimization are reviewed to show that many efforts have been involved in big data optimization in power system and systematically highlight some perspectives on big data optimization.

\subsection{Background}

Before starting the discussion about big data optimization, this section reviews the importance of big data projects. Analyzing the big data could release valuable information. Setting up a big data task is a challenge that requires many tasks and processes to be done alongside with data store.

To support a big data-based project, one first needs to analyze the data. There are specific data management tools for storing and analyzing large-scale data. Even in a simple project, there are several steps that must be performed. Figure 4.1 shows these steps that include data preparation, analysis, validation, collaboration, reporting, and access. They are briefed as follows:

- Data preparation is the process of collecting, cleaning, and consolidating data into one file or data table to be used in the analysis.

- Data analysis is the process of inspecting, cleansing, transforming, and modeling data to 
discover the useful information, draw conclusions, and support decision-making.

- Data validation is the process of ensuring that data have undergone a kind of cleansing to ensure they have acceptable quality and are correct and useful.

- Data collaboration means data visualization from all available different data sources while getting the data from the right people, in the right format, to be used in making effective decisions.

- Data reporting is the process of collecting and submitting data to authorities augmented with statistics.

- Data access typically refers to software and activities related to store, retrieve, or act on data housed in a database or other repository.

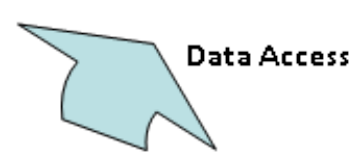

Reporting
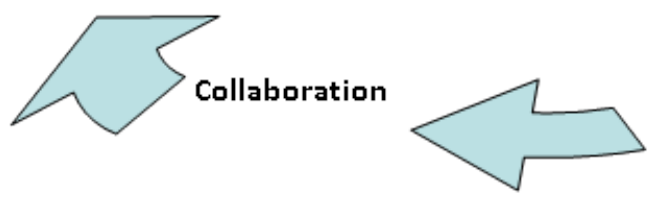
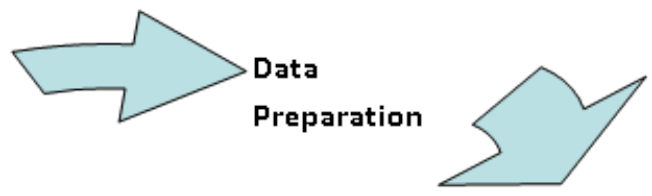

Analysis

Validation

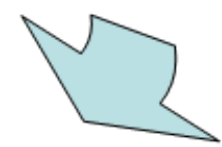

Figure 4.1: Process of data analysis

Big data analysis provides valuable opportunities to support decision-making in several areas, including education, and manufacturing, healthcare. For instance, big data analytics have helped yield healthcare improvements by providing personalized medicine and prescriptive analytics, while in manufacturing big data analysis provides an infrastructure for transparency in the manufacturing industry, which is the ability to unravel uncertainties such as inconsistent component performance and availability. An example of big data in science is the NASA Center for Climate Simulation (NCCS) that stores 32 petabytes of climate observations and simulations 
on a discover supercomputing cluster. Amazon, eBay, Facebook, and Google are some examples of the application of big data in today’s technology. Also, McKinsey Global Institute is known as an entity that applies big data in educational aspects. Table 4.1 presents some areas of big data applications in different fields, additional examples can be found in (Bihl et al., 2016).

Table 4.1: Application of big data

\begin{tabular}{cc}
\hline Area & Scholars \\
\hline Healthcare & $\begin{array}{c}\text { (Huser and Cimino (2016), O'donoghue and Herbert } \\
\text { (2012), Mirkes et al. (2016), Murdoch and Detsky } \\
\text { (2013) })\end{array}$ \\
Manufacturing & (Lee et al. (2014b), Li et al. (2015), Lee et al. \\
(2015)) & (Guide (2013), Brumfiel (2011), Francis (2012), \\
Swan (2013)) & (Tay (2010), Johnson (2010), Sullivan (2015), \\
Layton (2013)) & (Manyika et al. (2011), Picciano (2012), West \\
(2012)) & (Smith et al. (2012), Xu et al. (2016), Couldry and \\
Technology & Turow (2014), Burgess and Bruns (2012)) \\
\hline
\end{tabular}

\subsection{Scientometric analysis of big data}

Every activity in the 21st century such as financial transactions, research, sales and purchase, security, transport, automobile sectors, internet, and others, requires data. With the advances in technology and fast development of the internet, people observe the extent of data and 
information that enable access to vast amounts of data in a simple manner. However, this also needs a large amount of data with suitable storage capacity to host them. Nowadays, data manipulation techniques and computational capacities are some of the issues arising from big data, in which the classic technologies are not able to deal with them. Many researchers are working to resolve these problems in various areas such as health, economic, business, physics, and social sectors.

To highlight and show the importance of big data in today's power systems, scientometric technique and social network analysis (SNA) are used in the literature review. Recently, these techniques have become widespread because they facilitate understanding of some dynamical features such as collaboration among scholars (Emrouznejad and Marra (2016), De Stefano et al. (2011), Lee et al. (2014a)). Simply, they are known as strategic intelligence tools for the control of an emerging technology Rotolo et al. (2014).

Scientometric, is a key enabler that observes scientific publications to explore the structure and growth of a specific science using some quantitative measures of scientific information, as the number of scientific articles published in a given period, their citation impact, etc (Rajendran et al., 2011). The main idea is to visualize data on behalf of a principal subject area to signify the whole activities in scientific output. The scientometric mapping technique is used to find the most common keywords that were used in recent research articles. For this aim, the title 'largescale power system' is searched in SCOPUS database which recalled about 1107 scientific articles. Figure 4.2 presents the distribution of these papers from the 1970s. 


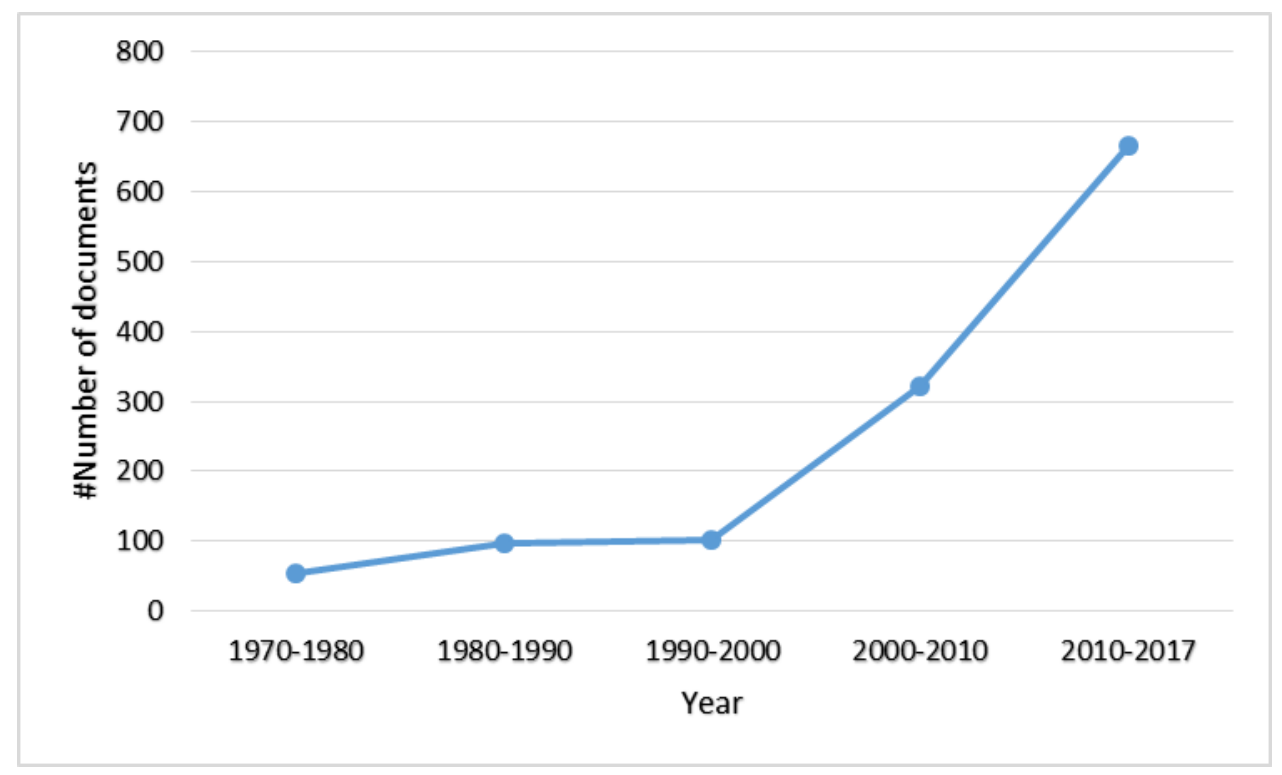

Figure 4.2: A number of publications on 'Large-scale power system.

Figure 4.3 presents a cognitive map where the size of the node is the equivalent number of publications on the considered term. Links among disciplines are shown by a lie whose density is proportional to the level of which two topics were being used in one article. The color of an item is managed by the cluster to which it belongs. 


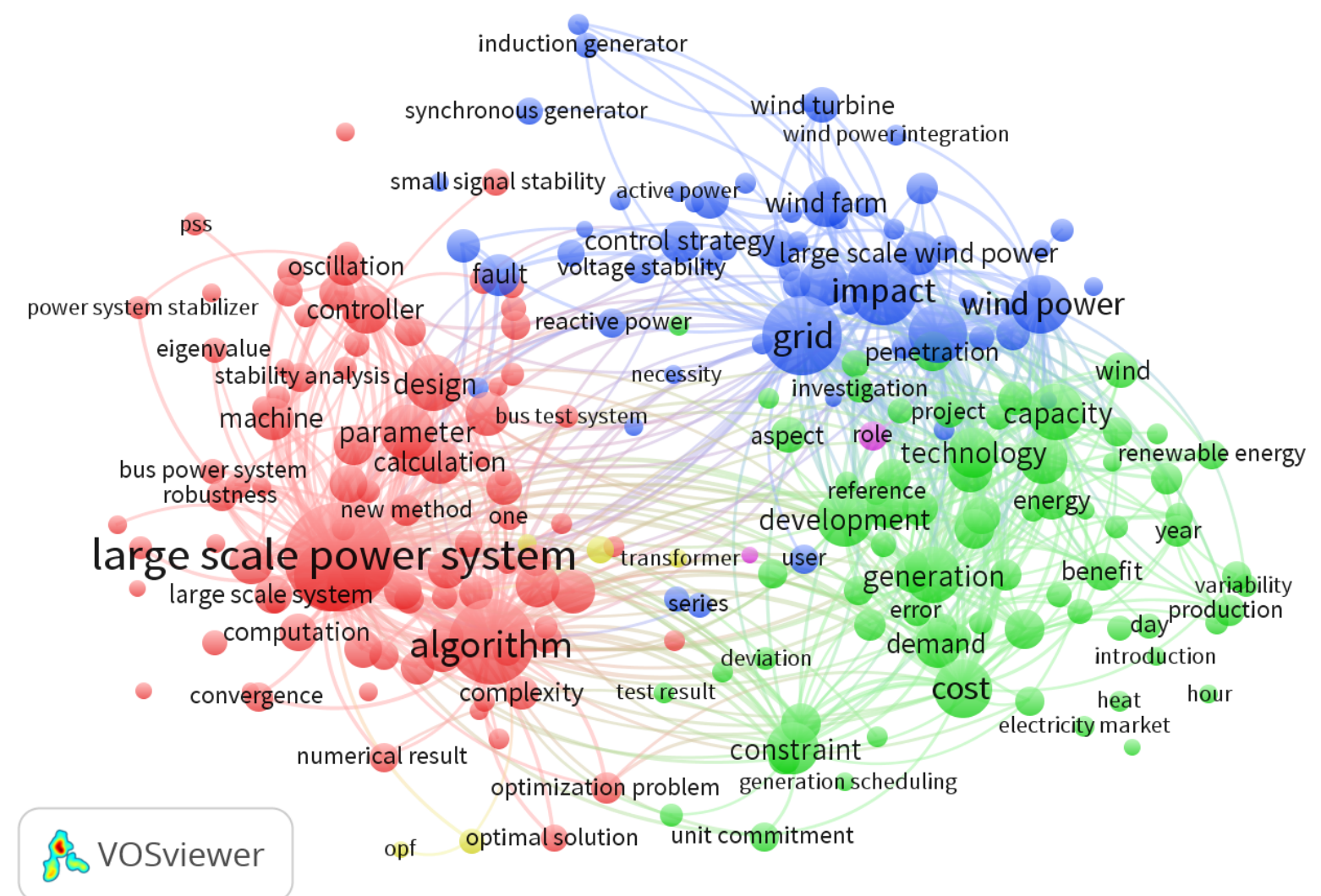

Figure 4.3: Cognitive map (keyword search based on co-occurrences)

The most commonly used keywords (ten keywords) and their number of occurrences have been given in Table 4.2. The objective of keyword analysis is to analyze the terms in a good accuracy. The process mainly depends on brainstorming to find the keywords which still have a high number of searches.

Table 4.2: The most commonly used keywords in big data optimization literature

\begin{tabular}{lll}
\hline No. & Keyword & Occurrences \\
\hline 1 & Large-scale power system & 399 \\
2 & Algorithm & 248 \\
3 & Grid & 211 \\
4 & Technique & 166 \\
5 & Impact & 152 \\
\hline
\end{tabular}




\begin{tabular}{lll}
\hline 6 & Wind power & 119 \\
7 & Cost & 116 \\
8 & Integration & 114 \\
9 & Capacity & 110 \\
10 & Development & 107 \\
\hline
\end{tabular}

Figure 4.4 presents a different visualization of a country map that indicates collaboration among authors from different countries by lines. Authors from around 101 countries have collaborated in developing articles in big data and power systems. Figure 4.4 shows that China is the most active country in the power system field, then, the USA and Japan are at the second and third stages, respectively. Table 4.3 presents rank of the top five organizations, which have been addressed in affiliations of authors, with respect to the number of documents and citations. Table 4.3: Rank of the top 5 organizations by number of documents

\begin{tabular}{llll}
\hline No. & Organization & Number of documents & $\begin{array}{l}\text { Number of } \\
\text { citations }\end{array}$ \\
\hline 1 & China Electric Power Research Institute & 9 & 110 \\
2 & North China Electric Power University & 7 & 247 \\
3 & Tsinghua University & 4 & 36 \\
4 & University of Queensland & 4 & 40 \\
5 & Brunel University & 4 & 6 \\
\hline
\end{tabular}




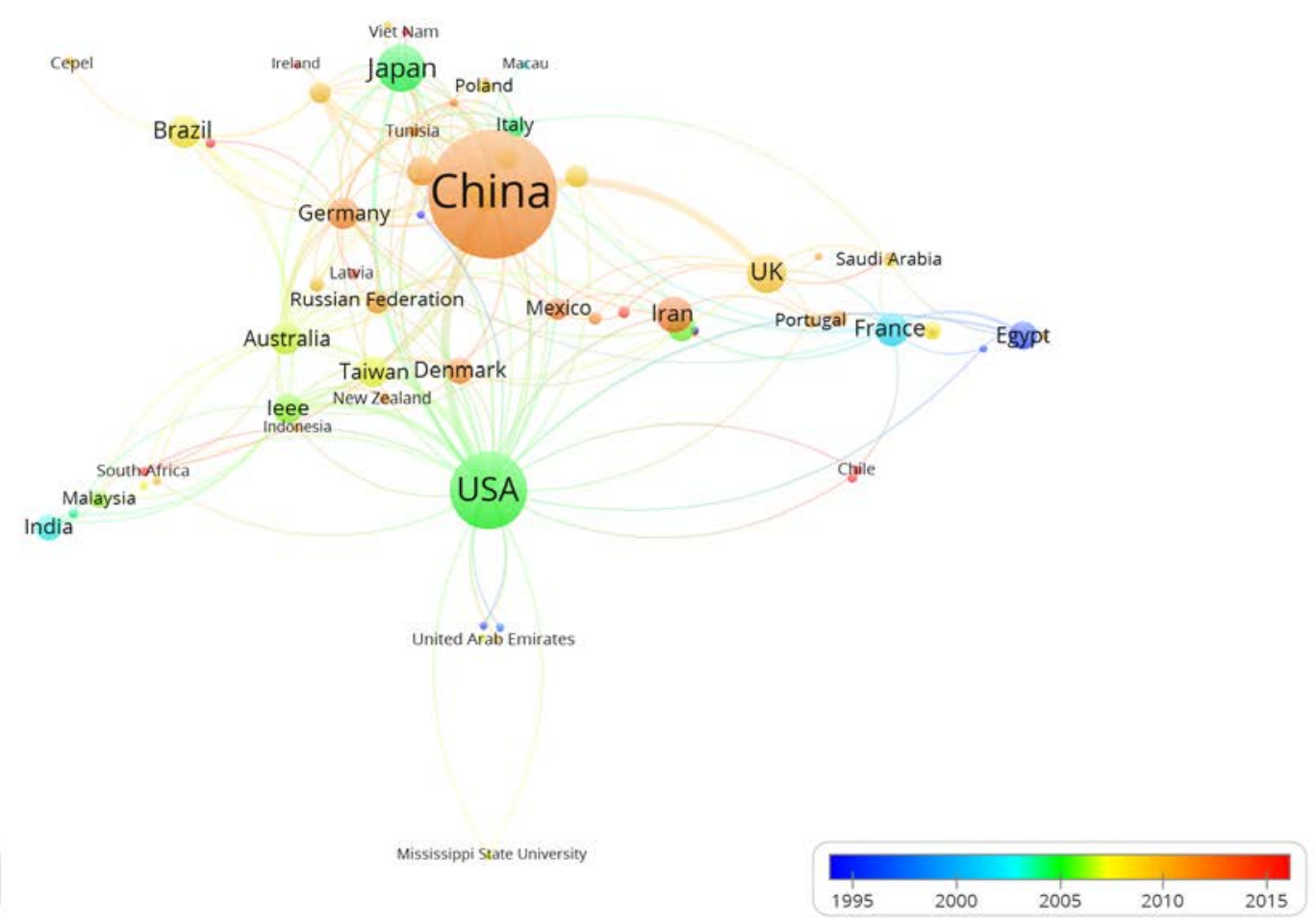

Figure 4.4: Network visualization (collaboration between countries)

Also, collaboration among authors has been analyzed. Figure 4.5 presents co-author collaborations to display the robust and fruitful connections among collaborating researchers. The links across the networks in Figure 4.5 shows the scientific communities involved in research on power systems and large-scale problems. 


\section{\& \&OSviewer}
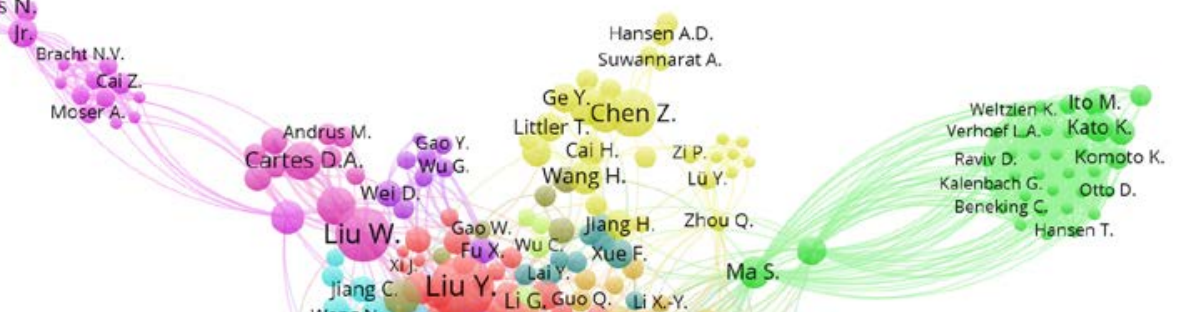

Figure 4.5: Scientific community (co-author) working on the large-scale power system

Figures 4.6 and 4.7 show network visualization and density map of the active journals in power system and large-scale problems based on citation analysis. Figure 4.6 presents the journals aggregated by density. The color shows the density, where the red color indicates a high density of a journal, while the blue color indicates the low-density journals. The right side of Figure 4.7 shows the densest area, occupied by journals dealing with the power system. The most frequent hosting sites are IEEE Transaction on Power System, Applied Mechanics and Material, Power System Protection and Control, Automation of Electric Power System, IEEE Power and Energy Society General Meeting, International Journal of Electrical Power and Energy Systems, and Proceedings of the Chinese Society of Electrical Engineering. 
2008 12th Inte6hational Middle

Electric Power Systems Researc

IEEE Power And Energy Society

Journal of Computational Infor - IEEE Transactions On Power Sys

Dianli Xitong Zidonghua/Automa

Asia-Pacific Power And Energy

\section{象 Vosviewer}

Figure 4.6: Journal map (title) based on citation analysis

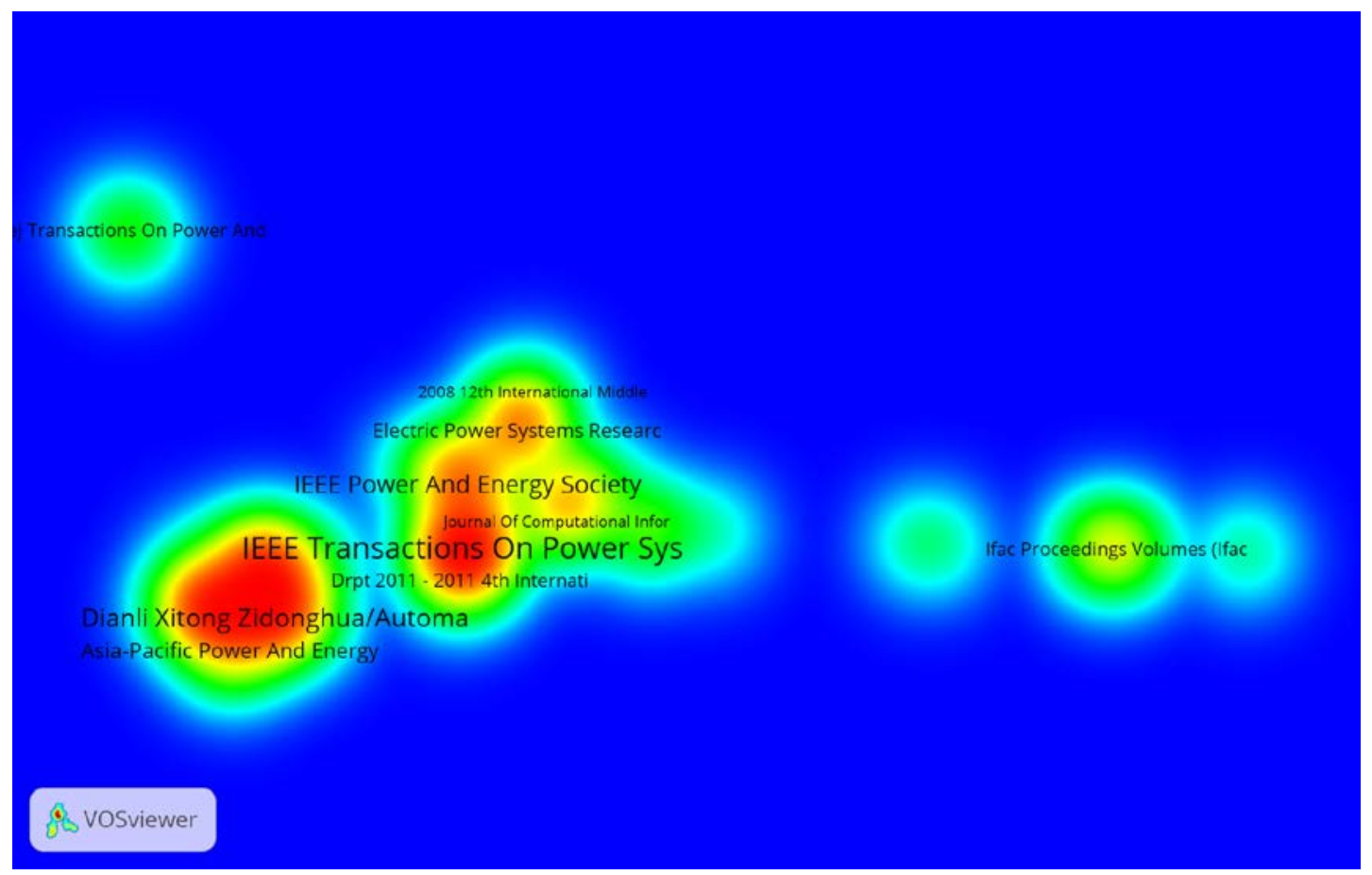

Figure 4.7: Density map (Journal title) based on citation analysis 
Figure 4.8 shows different analysis (co-citation) of cited journals which possesses a minimum of ten citations for each source, and this leads to 152 sources with co-citation links.

\footnotetext{
今 vosviewer
}

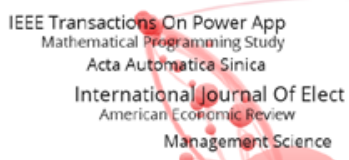

Figure 4.8: Network visualization (co-citation analysis)

\subsection{Big data and power systems}

There are many large-scale optimization problems in power system, especially in the cases which consider the uncertainty of input parameters (Charwand et al., 2015b, Esmaeel Nezhad et al., 2015, Ahmadi et al., 2013, Charwand et al., 2015a, Ahmadi et al., 2016, Mavalizadeh and Ahmadi, 2014, Sharafi Masouleh et al., 2016). Various researchers, c.f. (Charwand et al., 2015b, 
Esmaeel Nezhad et al., 2015, Ahmadi et al., 2013, Charwand et al., 2015a), consider the optimal operation of an electrical energy retailers. Ahmadi et al. (2016) proposes a stochastic programing for the optimal operation for a distribution company. Mavalizadeh and Ahmadi (2014) considers emission and security for generation and transmission expansion planning. (Sharafi Masouleh et al., 2016, Ahmadi et al., 2011) use a mixed integer linear model for the optimal operation of hydro generation units. (Moghimi et al., 2013, Ghadikolaei et al., 2012) investigate the effects of distributed energy resources in the short term optimal operation of power systems. (Esmaeily et al., 2017, Aghaei et al., 2015b, Karami et al., 2013, Aghaei et al., 2015a) suggest using a Roulette wheel mechanism and lattice Monte Carlo simulation methods for modeling of uncertainties in hydrothermal scheduling problem. (Charwand et al., 2015b, Esmaeel Nezhad et al., 2015, Ahmadi et al., 2013, Charwand et al., 2015a, Ahmadi et al., 2016, Mavalizadeh and Ahmadi, 2014, Sharafi Masouleh et al., 2016) have many integer variables, for example (Aghaei et al., 2015a) report that the last case study has 3,841,392 variables, 1,610,808 discrete variables, and 4,712,112 equations. This example shows that the number of variables and equations are high. In the following sections, the background of big data in power systems is presented along with applications and the most common approaches in big data optimization in power systems.

\subsubsection{Big data optimization}

Big data optimization is one of the important issues in big data areas that have been widely arisen with many challenges such as privacy, size of data, and data management (Zicari et al., 2016). Social network science, Machine learning, and biology are instances of many noticeable application fields where it is easy to formulate optimization problems with millions of variables. However, there is a necessity for powerful optimization algorithms for information processing to 
learn models as the size increase of data is becoming a global problem to solve large-scale optimization problems. Classical optimization algorithms are not planned to measure to cases of this size; new methods are required. Some examples of mathematical optimization in big data include logistics and supply chain issues (Gunasekaran et al., 2017, Papadopoulos et al., 2017, Wu et al., 2017, Kache et al., 2017, Zhao et al., 2017, Brouer et al., 2016), nonconvex optimization (Gong et al., 2016), unconstrained optimization (Babaie-Kafaki, 2016), and nonsmooth optimization (Karmitsa, 2016). Big data optimization is usually taken into account in power systems research like management and scheduling, power dispatch, and energy demand.

\subsubsection{Application of big data in power system studies}

The use of big data has increased in several ways so that private companies and governments are investing billions of dollars in data management and analysis (Cukier, 2010)). In power systems, data could be gathered from different sources such as renewables like solar and wind energies or other portions of energy technologies such as gas and fuel. In this regard, there are several applications of big data in energy domain that could be surveyed as renewables data use in biomass energy (Paro and Fadigas, 2011), marine energy (MacGillivray et al., 2014), (Wood et al., 2010), and wind energy (Billinton and Gao, 2008), (Kaldellis, 2002), energy consumption (Kung and Wang, 2015), or may consider energy demand response such as power demand (Liu et al. (2013), and storage capacity (Goyena et al. (2009), or could be analyzed as electric vehicles (EVs) (Jiang et al., 2016) such as driving pattern (Wu et al. (2010), energy management (Su and Chow (2012), energy efficiency (Midlam-Mohler et al. (2009), driving range (Rahimi-Eichi et al., 2015), (Lee and Wu, 2015), battery capacity (Shor, 1994), data quality (Zhang et al., 2015), and EVs state (Soares et al., 2015). 
Also, there are other challenges in storage and analysis of data, visualization, sharing, etc, (Boyd and Crawford, 2011). It is common to identify trends, spots of problems, and predictive analysis to gain useful information from data. However, it is a big challenge when the problem is faced with big data. So a feature that is necessary for a successful big data analytics system is the need to make the data "over-the-counter" for understanding and using the data satisfactorily. This is especially vital for "high-stakes data" used to make better decisions. Firms which are making plans for big data tend to propose methods that consume less expensive storage, and processing alternatives, as well as tools to enhance data management. However, some of the significant challenges respondents cited to big data implementation, are finding a staff to work in this domain and then training them while adjusting new methodologies for analytics and optimization.

\subsection{Optimization techniques used in the big data analysis}

Traditional optimization methods could not be used to scale the large data size correctly; thus, new methods are critically needed. Optimization techniques in big data include several issues such as optimization big images, intelligent reduction, optimization based on Hadoop, and mathematical and metaheuristic optimization (Emrouznejad 2016). There are numerous optimization methods that have been applied to power system operations. They are introduced, as follows:

4.5.1 Computational method for large-scale unconstrained optimization

In some big data optimization programming, there are many variables resulting in a need for high memory. One of these applications is called unconstrained optimization which has broad application in engineering, industry, economic, and other fields. Unconstrained optimization also 
emerges from rewriting of constrained optimization by replacing some penalty terms in objective functions with some constraints. In this way, there is some application of unconstrained optimization method in power system problems (Zhu, 2015). While there are several approaches to dealing with unconstrained optimization, a conjugate gradient method is a useful method to solve large-scale cases (Babaie-Kafaki, 2016). Conjugate gradient techniques were suggested by (Hestenes and Stiefel, 1952) that were used for solving the linear system. Required parameters for Hestenes-Stiefel (HS) Method are introduced as follows:

$\beta_{k}^{H S}=\frac{g_{k+1}^{T}}{d_{k}^{T} y_{k}} \quad \mathrm{~K}=0,1, \ldots$

where $d_{k}$ is the search direction which is computed by inner products. This direction should be descent direction which means $g_{k}^{T} d_{k}<0$, and $g_{k}=\nabla O F\left(x_{k}\right)$ where $O F$ is a smooth nonlinear function that needs to be minimized, where $y_{k}=g_{k+1}-g_{k}$.

Regarding the mean value- theorem $\exists \zeta \in(0,1)$, thus

$d_{k+1}^{T} y_{k}=d_{k+1}^{T}\left(g_{k+1}-g_{k}\right)=\alpha_{k} d_{k+1}^{T} \nabla^{2} F\left(x_{k}+\zeta \alpha_{k} d_{k}\right) d_{k}$

$\alpha_{k}$ is a step length that is determined by the line search, and the condition $d_{k+1}^{T} y_{k}=0$ can be considered as a conjugacy condition. Conjugate gradient methods include algorithms that are between Newton and steepest descent methods. Steepest descent method (Cauchy, 1847), Newton method (Sun and Yuan, 2006, Watkins, 2004), conjugate direction method (BabaieKafaki, 2016), quasi-newton method (Sun and Yuan, 2006), are also applied for unconstrained optimization problems. Using the Hessian information; the techniques affect the direction of steepest descent. One of the weaknesses of the steepest descent technique was the slow convergence of the algorithm. In this regard, the method only needs the first-order derivatives 
while the Newton method needs second-order derivative. These methods are broadly used for solving large-scale optimization problems.

\subsubsection{Numerical approach for non-smooth large-scale optimization}

Definition of smooth functions arises from the first derivative (slope or gradient) at every point. In a graphical view, there is no abrupt in a smooth function of a single variable and also can be

plotted as a single continuous, for example, the logistic loss $f(x)=\log (1+\exp (-x))$ is a smooth function. In contrast, non-differentiable and discontinuous functions are classified as non-smooth functions. Moreover, some functions with first derivatives also called non-differentiable. Graphs of non-differentiable functions may have abrupt bends, e.g. $f(x)=|x|$. These types of optimization are introduced as minimizing or maximizing which are broad in many applications such as economic (Outrata et al., 2013), engineering (Mistakidis and Stavroulakis, 2013), data analysis (Astorino and Fuduli, 2007, Astorino et al., 2008, Äyrämö, 2006), and control problem (Clarke et al., 2008). These problems are mostly large-scale. However, small-scale are also difficult to be solved (Karmitsa, 2016). The Boudle method is one of the techniques which could tackle large-scale non-smooth optimization problem. There are two kinds of the bundle method called, limit memory bundle method (LMBM) and diagonal bundle method (D-bundle). Bundle method has also applied in different power system applications such as uncertainty (Bacaud et al., 2001), scheduling (Zhang et al., 1999, Mezger and de Almeida, 2007), decomposition algorithms (Borghetti et al., 2003, Belloni et al., 2003). Some scholars have presented some works for nonsmooth functions (Attaviriyanupap et al. (2002), (Liu and Cai, 2005), Dotta et al. (2009), Roy et al. (2010)). 


\subsubsection{Big data in logistics optimization}

Logistics refers to actions which occur within the boundaries of single firms and supply chain mentions to networks of organizations which work together and coordinate their activities to deliver a product to market. Levels of the decision in the supply chain as illustrated in Figure 4.9, and include three levels (Schmidt and Wilhelm, 2000). Decisions which determine the fleet size in marine logistics, for example, and facility location and layout belong to the strategic level. The logistics network may be possible to serve vast size of customers up to thousands of customers for or a particular network. Operational level involves vehicle routing through transportation network, loading products, the landing of vessels, while tactical level production schedule and individual services (Brouer et al., 2016). However Seaborn constitutes in the logistics network, around $80 \%$ of transportation. In this case, network design problem is a primary planning problem in the logistics network. Regarding the demands which should be transported and selecting ports for servicing to supply chain decision makers wish to draw routes for their career to satisfy requirements of customers. 


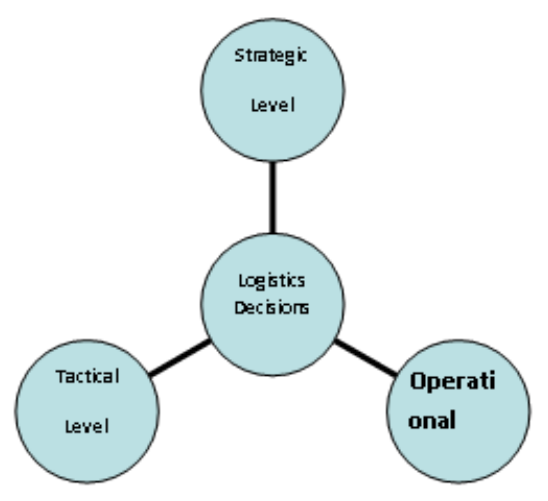

Figure 4.9: Different logistics decisions (Schmidt and Wilhelm, 2000)

Sheu (2008) proposed a novel multi-objective optimization programming model to optimize operations in nuclear power generation (Taiwan nuclear power generation firm) and reduce waste logistics. The author has considered risk reduction in the formulation. The result depicts the improvement of performance from $7.41 \%$ to $18.37 \%$, and risks were also reduced by $37.75 \%$.

4.5.4 Big data analytics based on convex and nonconvex optimization Mathematically, a single objective minimizing (maximizing) optimization could be presented as follows:

$$
\begin{aligned}
& \min (\max ) O F(x) \\
& \text { s.t. } g_{i}(x) \leq 0, i=1, \ldots, m \\
& x \in D
\end{aligned}
$$

where $x$ is called a decision vector and $D$ is the feasible region. $O F$ is an objective function, and $g$ is constrained to function. Convexity condition for $f$, given $D$, holds:

$$
O F\left(\lambda x_{1}+(1-\lambda) x_{2}\right) \leq \lambda O F\left(x_{1}\right)+(1-\lambda) O F\left(x_{2}\right) \quad \forall x 1 \neq x 2 \in D, \forall \lambda \in[0,1]
$$


Moreover, $O F$ is strictly convex if the following condition holds:

$$
O F\left(\lambda x_{1}+(1-\lambda) x_{2}\right)<\lambda O F\left(x_{1}\right)+(1-\lambda) O F\left(x_{2}\right) \quad \forall x 1 \neq x 2 \in D, \forall \lambda \in[0,1]
$$

Equation (4.3) is called convex optimization problem if both functions $O F$ and $g$ are convex. There is a possibility to find a global solution for equation (4.3) if OF was convex. However, many real cases face the nonconvex optimization problem. In these cases, researchers try to find the local or global solution (Grossmann, 2013, Mistakidis and Stavroulakis, 2013). One of the relevant optimization problems in power system is known as the economic dispatch (ED). In the ED, the objective is defined allocating power demand among power plants in the most economic situation such that all operational constraints are satisfied. The cost function represents the quadratic fuel cost, and the valve-point effects cost which makes the objective function discontinuous, nonconvex. Selvakumar and Thanushkodi (2007) have applied a new particle swarm optimization (PSO) approach for nonconvex ED problem and suggested a new method in PSO based on the worst position of the particle and integrated it with local random search (LRS) and validated the proposed solution methodology with three economic dispatch tests. Their proposed algorithm shows significant improvement in convergence to the solution. Chaturvedi et al. (2009) used the PSO with time-varying acceleration coefficient in such a way that controls global and local search to achieve the global solution.

In many real applications, there are several objectives to be optimized. Multi-objective optimization usually includes conflict functions, in which improving one function lead to deterioration of the other one, so there is no single solution that can optimize all the functions together. In this case, researchers are looking for Pareto optimal solutions which are good compromising solutions. Equation (4.6) shows a multi-objective problem: 
$\operatorname{Min}(\operatorname{Max}) O F=\left\{O F_{1}(x), O F_{2}(x), \ldots, O F_{n}(x)\right\}$,

s.t.

$x \in D$

Vector $x \in D$ is called Pareto solution to the problem (4.6) if there is no $x^{*}$ such that

$O F_{i}\left(x^{*}\right) \leq O F_{i}(x)$ for any $i=1, \ldots, n$ and $\exists j(1 \leq j \leq n): O F_{j}\left(x^{*}\right)<O F_{j}(x)$. If $O F\left(x^{*}\right) \leq O F(x)$, it is said that $x^{*}$ is a non-dominated solution. Guo et al. (2016) applied distributed optimization for a large scale non-convex transmission network. The authors applied spectral partitioning approach alongside the distributed optimization method, known as alternating direction method of multipliers (ADMM) to solve a nonconvex problem. In their work, they have shown that the solution found by ADMM is almost close to a local optimum.

4.5.5 Metaheuristic algorithms for big data optimization

Several new challenges have brought with the age of big data. Regarding optimization, researchers may face large-scale size problems, including hundreds, thousands, and even millions of variables. Several techniques have introduced and developed for tackling high dimensional optimization problems. Among them, metaheuristic algorithms are known as efficient algorithms with high computing performance. Several scholars have used metaheuristic algorithms in power system (Chiang, 2016, Camillo et al., 2016, Rajesh et al., 2016, Chen and Chang, 1995, Lee and Yang, 1998). There are significant open research fields and issues for improvement. Among metaheuristic algorithms, evolutionary algorithms are known as a great powerful technique for continuous global optimization. However, increasing the number of variables resulting in deteriorating performance of the algorithm. There is a need for suitable approaches for dealing large scale size problem to find global solutions to the optimization problems. Many scholars have attempted to face this difficulty (Wang et al., 2010, Yan et al., 
2004, Chiou, 2007, Lin et al., 2017, Beigvand et al., 2017). An ED is a significant tool in power system operations, which schedules committed generating to meet demand in a point at a minimum cost (Beigvand et al., 2017). Beigvand et al. (2017) proposed hybridization of PSO and the Gravitational Search Algorithm (GSA) for a large-scale, non-convex, non-smooth, nonlinear, and non-continuous combined heat and power dispatch. Summary of (Beigvand et al., 2017) proposed algorithm is presented in Figure 4.10.

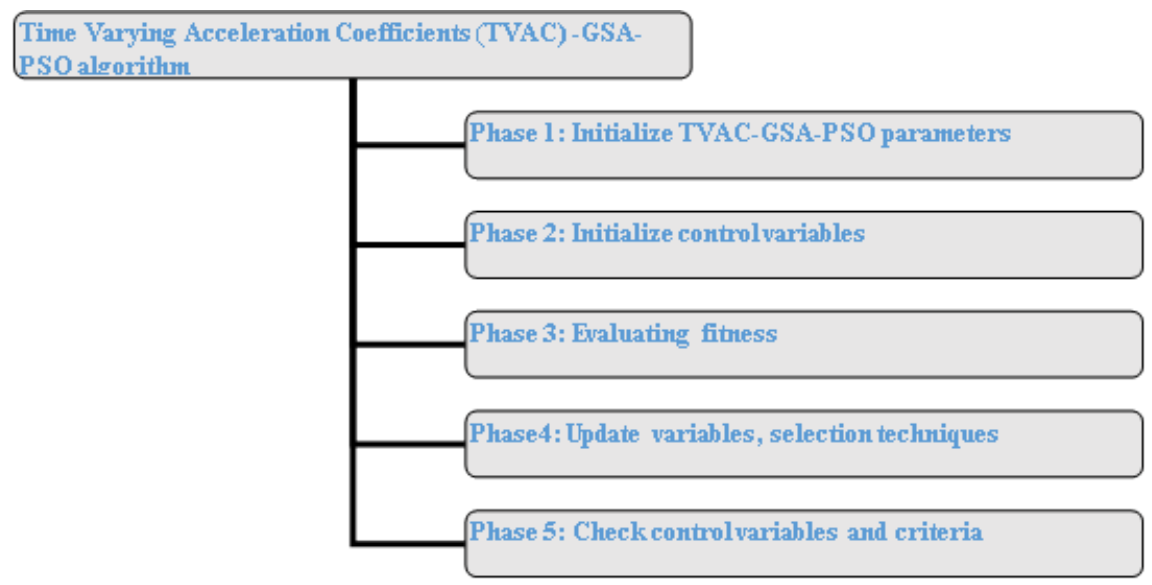

Figure 4.10: Phase classification for Hybrid algorithm

The authors have compared results with several optimization algorithms such as culture PSO (CPSO), modified PSO (MPSO), orthogonal teaching learning-based optimization (OTLBO), and teaching learning-based optimization (TLBO), GSA. Regarding robustness, the suggested method has better performance than other solution optimization methods. Moreover, the results show hybrid algorithm has saved computational time significantly. Quality solution and the convergence speed of the hybrid algorithm possess superior performance than other optimization algorithms. Using of renewable energy has attracted the attention of power system planners across the world. Rajesh et al. (2016) applied differential evolution algorithm in a model of a solar plant to minimize both emission and cost. In the model, the data were gathered from 
demand and plants, then the model is generated based on assumption. After several studies, the model is developed, and a solution methodology has been selected for the proposed model. A sensitivity analysis was applied to the proposed model, and finally, the future power system model is generated with characteristics such as total cost, capacity additions, emission level. Naderi et al. (2017) proposed a fuzzy adaptive, comprehensive -learning particle swarm optimization known as FAHCLPSO for the large-scale power dispatch optimization problem. Objective functions for the proposed algorithm include minimizing the active power transmission losses and improving the voltage profile of the system. The authors have validated the performance of their suggested algorithm with three different tests, including IEEE 30-bus, IEEE 118-bus, and IEEE 354-bus test systems. The authors have claimed that the proposed algorithm (FAHCLPSO) was the first applied for optimal reactive power dispatch. They have used fuzzy logic to enhance the searchability of the algorithm.

Table 4.4 and Table 4.5 review classification of metaheuristic methods which have been carried out by scholars. Population-based approaches introduce most techniques and classified by evolutionary computations such as PSO, genetic algorithm (GA), Tabu search (TS), AND ant colony optimization (ACO). 
Table 4.4: Literature of metaheuristic classification for power system problems

Metaheuristic

\begin{tabular}{|c|c|c|c|c|c|c|c|c|}
\hline \multicolumn{6}{|l|}{ Population } & \multirow[t]{3}{*}{ Trajectory } & \multirow[t]{3}{*}{ Implicit } & Local search \\
\hline \multicolumn{6}{|c|}{ Naturally inspired } & & & No memory \\
\hline & & Implicit & Explicit & Direct & & & & \\
\hline $\begin{array}{l}\text { Genetic } \\
\text { algorithm }\end{array}$ & Ant colony & $\begin{array}{l}\text { Evolutionary } \\
\text { programming }\end{array}$ & Differential evolution & $\begin{array}{l}\text { Simulated } \\
\text { annealing }\end{array}$ & PSO & Tabu search & $\begin{array}{l}\text { Scatter } \\
\text { search }\end{array}$ & $\begin{array}{l}\text { Stochastic local } \\
\text { search }\end{array}$ \\
\hline $\begin{array}{l}\text { Chiang (2005) } \\
\text { Gerbex et al. } \\
\text { (2001) } \\
\text { Walters and } \\
\text { Sheble (1993) }\end{array}$ & $\begin{array}{l}\text { Hou et al. (2002) } \\
\text { Hou et al. (2003) } \\
\text { Niu et al. (2010) }\end{array}$ & $\begin{array}{l}\text { Khatod et al. } \\
\text { (2013) } \\
\text { Tsai and Hsu } \\
\text { (2010) } \\
\text { Chung et al. } \\
\text { (2010) } \\
\text { (Yang et al., 1996) }\end{array}$ & $\begin{array}{l}\begin{array}{l}\text { Lakshminarasimman } \\
\text { and Subramanian (2006) }\end{array} \\
\text { Liang et al. (2007) } \\
\text { Su and Lee (2003) } \\
\text { Sayah and Zehar (2008) }\end{array}$ & $\begin{array}{l}\text { Abido (2000) } \\
\text { Zhuang and } \\
\text { Galiana (1990) } \\
\text { Basu (2005) }\end{array}$ & $\begin{array}{l}\text { Surendra and } \\
\text { Parthasarathy } \\
\text { (2014) } \\
\text { Syahputra and } \\
\text { Soesanti (2015) } \\
\text { Pan and Das } \\
\text { (2016) }\end{array}$ & $\begin{array}{l}\text { Lin et al. (2002) } \\
\text { Abido (1999) } \\
\text { Mori and Goto } \\
\text { (2000) }\end{array}$ & $\begin{array}{l}\text { de Silva et } \\
\text { al. (2013) } \\
\text { Mori and } \\
\text { Shimomugi } \\
\text { (2007) } \\
\text { Mizutani et } \\
\text { al. (2005) }\end{array}$ & $\begin{array}{l}\text { Das and Patvardhan } \\
\text { (1998) } \\
\text { Das and Patvardhan } \\
\text { (2002) } \\
\text { Hoos and Stützle } \\
(2004)\end{array}$ \\
\hline
\end{tabular}


Table 4.5: Literature of metaheuristic classification for power system problems (continued)

\begin{tabular}{|c|c|c|c|c|c|c|c|c|}
\hline \multicolumn{9}{|c|}{ Metaheuristic } \\
\hline \multicolumn{6}{|l|}{ Population } & \multirow[t]{3}{*}{ Trajectory } & \multirow[t]{3}{*}{ Implicit } & Local search \\
\hline \multicolumn{6}{|c|}{ Naturally inspired } & & & \multirow[t]{2}{*}{ No memory } \\
\hline & & Implicit & Explicit & Direct & & & & \\
\hline $\begin{array}{l}\text { Genetic } \\
\text { algorithm }\end{array}$ & Ant colony & $\begin{array}{l}\text { Evolutionary } \\
\text { programming }\end{array}$ & $\begin{array}{l}\text { Differential } \\
\text { evolution }\end{array}$ & $\begin{array}{l}\text { Simulated } \\
\text { annealing }\end{array}$ & PSO & Tabu search & Scatter search & $\begin{array}{l}\text { Stochastic local } \\
\text { search }\end{array}$ \\
\hline $\begin{array}{l}\text { Panda and } \\
\text { Yegireddy } \\
\text { (2013) } \\
\text { Apribowo and } \\
\text { Hadi (2016) } \\
\text { Kaur et al. } \\
\text { (2017) }\end{array}$ & $\begin{array}{l}\text { Pothiya et al. } \\
\text { (2010) } \\
\text { Fetanat and } \\
\text { Shafipour (2011) } \\
\text { Besheer and } \\
\text { Adly (2012) }\end{array}$ & $\begin{array}{l}\text { Wu and Ma (1995) } \\
\text { Yuryevich and } \\
\text { Wong (1999) } \\
\text { Lai (1998) }\end{array}$ & $\begin{array}{l}\text { Cai et al. (2008) } \\
\text { Shaheen et al. } \\
\text { (2011) } \\
\text { Wang et al. (2009) }\end{array}$ & $\begin{array}{l}\text { Abido (2000) } \\
\text { Romero et al. } \\
\text { (1995) } \\
\text { Lyden and Haque } \\
\text { (2016) }\end{array}$ & $\begin{array}{l}\text { Ahila et al. (2015) } \\
\text { Abderrezek et al., } \\
\text { (2016) } \\
\text { Rouhi and } \\
\text { Effatnejad (2015) } \\
\text { Park et al. (2005) } \\
\text { Niknam (2010) } \\
\text { (Park et al., 2003) }\end{array}$ & $\begin{array}{l}\text { Ramírez-Rosado and } \\
\text { Domínguez-Navarro } \\
\text { (2006) } \\
\text { Katsigiannis et al. } \\
\text { (2016) } \\
\text { Asadpour et al. } \\
\text { (2015) }\end{array}$ & $\begin{array}{l}\text { Habibi et al. } \\
(2014) \\
\text { Castillo et al. } \\
(2007) \\
\text { de Padua et al., } \\
(2015)\end{array}$ & $\begin{array}{l}\text { Hoos (1998) } \\
\text { Newton et al. } \\
\text { (2013) } \\
\text { (Fukuta and Ito } \\
\text { (2011)) }\end{array}$ \\
\hline
\end{tabular}




\subsection{Conclusion}

The chapter overviewed big data optimization issues in electric power systems. The scientific communities, distribution of publications, and collaboration among researchers around the world have been analyzed. The different types of big data optimization in power system have been discussed. Different types of complicated optimization problems in power systems were discussed. For this aim, factors such as nonlinearity of objective functions, number of variables, Nonsmooth functions were reviewed. One of the most difficulties dealing with these kinds of big data problems relates to the solution approach as addressed.

Because of the ongoing efforts in organizing smart grid infrastructure, the utility business is facing new challenges in dealing with big data and using them to improve decision-making. Big data in the electric power industry can be described in terms of volume, velocity, variety, veracity, value, or all the five terms. Usually, utilities do not handle data using an individual, consistent data management structure which makes ad hoc use of the new decision-making packages needlessly complex. Although analysis of data is accessed through different data, if the data are not timed and spatial, unless they have a common data syntax and semantics for ease of use and if it is not fit for the uniform and common combination of the power system model, such analysis is perhaps not easy to implement. Moreover, one of the most challenging issues in power systems for decision makers arise from optimization problems.

In addition, the chapter shows a significant effort involved in large-scale handling optimization which led to several algorithms, including mathematical optimization and metaheuristic optimizations, which metaheuristic optimizations that have proven to be more accurate, more efficient, and faster than earlier algorithms. Issues such as logistics optimization as well as 
Nonsmooth, nonconvex, and unconstrained large-scale optimization are presented. Finally, some metaheuristic methods in large-scale power system optimization are reviewed.

\subsection{References}

Abido, M. 1999. A novel approach to conventional power system stabilizer design using tabu search. International Journal of Electrical Power \& Energy Systems, 21, 443-454.

Abido, M. 2000. Robust design of multimachine power system stabilizers using simulated annealing. IEEE transactions on Energy conversion, 15, 297-304.

Aghaei, J., Ahmadi, A., Rabiee, A., Agelidis, V. G., Muttaqi, K. M. \& Shayanfar, H. A. 2015a. Uncertainty management in multiobjective hydro-thermal self-scheduling under emission considerations. Applied Soft Computing, 37, 737-750.

Aghaei, J., Karami, M., Muttaqi, K. M., Shayanfar, H. A. \& Ahmadi, A. 2015b. MIP-based stochastic security-constrained daily hydrothermal generation scheduling. IEEE Systems Journal, 9, 615-628.

Ahila, R., Sadasivam, V. \& Manimala, K. 2015. An integrated PSO for parameter determination and feature selection of ELM and its application in classification of power system disturbances. Applied Soft Computing, 32, 23-37.

Ahmadi, A., Aghaei, J. \& Shayanfar, H. Stochastic self-scheduling of hydro units in joint energy and reserves markets. Electrical Engineering (ICEE), 2011 19th Iranian Conference on, 2011. IEEE, 1-5.

Ahmadi, A., Charwand, M. \& Aghaei, J. 2014. Risk-constrained optimal strategy for retailer forward contract portfolio. International Journal of Electrical Power \& Energy Systems, 53, 704-714.

Ahmadi, A., Charwand, M., Siano, P., Nezhad, A. E., Sarno, D., Gitizadeh, M. \& Raeisi, F. 2016. A novel two-stage stochastic programming model for uncertainty characterization in shortterm optimal strategy for a distribution company. Energy, 117, 1-9.

Apribowo, C. H. B. \& Hadi, S. P. Design of experiments to parameter setting in a genetic algorithm for optimal power flow with TCSC device. Industrial, Mechanical, Electrical, and Chemical Engineering (ICIMECE), International Conference of, 2016. IEEE, 73-78.

Asadpour, M., Ajhiri, F. A., Tazehkand, B. M. \& Seyedarabi, M. H. 2015. Jointly RVM Based Channel Estimation and PAPR Reduction Using Modified Tabu Search Algorithm in Power Line Communication Systems. Wireless Personal Communications, 84, 2757-2775. 
Astorino, A. \& Fuduli, A. 2007. Nonsmooth optimization techniques for semisupervised classification. IEEE Transactions on Pattern Analysis and Machine Intelligence, 29, 2135-2142.

Astorino, A., Fuduli, A. \& Gorgone, E. 2008. Non-smoothness in classification problems. Optimisation Methods \& Software, 23, 675-688.

Attaviriyanupap, P., Kita, H., Tanaka, E. \& Hasegawa, J. 2002. A hybrid EP and SQP for dynamic economic dispatch with nonsmooth fuel cost function. IEEE Transactions on Power Systems, 17, 411-416.

Äyrämö, S. 2006. Knowledge mining using robust clustering, University of Jyväskylä.

Babaie-Kafaki, S. 2016. Computational Approaches in Large-Scale Unconstrained Optimization. Big Data Optimization: Recent Developments and Challenges. Springer.

Bacaud, L., Lemaréchal, C., Renaud, A. \& Sagastizábal, C. 2001. Bundle methods in stochastic optimal power management: A disaggregated approach using preconditioners. Computational Optimization and Applications, 20, 227-244.

Basu, M. 2005. A simulated annealing-based goal-attainment method for economic emission load dispatch of fixed head hydrothermal power systems. International Journal of Electrical Power \& Energy Systems, 27, 147-154.

Beigvand, S. D., Abdi, H. \& La Scala, M. 2017. Hybrid Gravitational Search Algorithm-Particle Swarm Optimization with Time Varying Acceleration Coefficients for large scale CHPED problem. Energy, 126, 841-854.

Belloni, A., Lima, A. D. S., Maceira, M. P. \& Sagastizábal, C. A. 2004. Bundle relaxation and primal recovery in unit commitment problems. The Brazilian case. Annals of Operations Research, 120, 21-44.

Besheer, A. \& Adly, M. Ant colony system based PI maximum power point tracking for stand alone photovoltaic system. Industrial Technology (ICIT), 2012 IEEE International Conference on, 2012. IEEE, 693-698.

Billinton, R. \& Gao, Y. 2008. Multistate wind energy conversion system models for adequacy assessment of generating systems incorporating wind energy. IEEE Transactions on Energy Conversion, 23, 163-170.

Borghetti, A., Frangioni, A., Lacalandra, F. \& Nucci, C. A. 2004. Lagrangian heuristics based on disaggregated bundle methods for hydrothermal unit commitment. IEEE Transactions on Power Systems, 18, 313-324. 
Boyd, D. \& Crawford, K. Six provocations for big data. A decade in internet time: Symposium on the dynamics of the internet and society, 2011. Oxford Internet Institute Oxford.

Brouer, B. D., Karsten, C. V. \& Pisinger, D. 2016. Big Data Optimization in Maritime Logistics. Big Data Optimization: Recent Developments and Challenges. Springer.

Brumfiel, G. 2011. Down the petabyte highway. Nature, 469, 282-284.

Burgess, J. \& Bruns, A. 2012. Twitter archives and the challenges of" Big Social Data" for media and communication research. M/C Journal, 15.

Cai, H., Chung, C. \& Wong, K. 2008. Application of differential evolution algorithm for transient stability constrained optimal power flow. IEEE Transactions on Power Systems, 23, 719-728.

Camillo, M. H., Fanucchi, R. Z., Romero, M. E., De Lima, T. W., Da Silva Soares, A., Delbem, A. C. B., Marques, L. T., Maciel, C. D. \& London, J. B. A. 2016. Combining exhaustive search and multi-objective evolutionary algorithm for service restoration in large-scale distribution systems. Electric Power Systems Research, 134, 1-8.

Castillo, A., Ortiz, J. J., Perusquía, R., Hernandez, J. \& Montes, J. 2007. Control rod pattern design using scatter search.

Cauchy, A. 1847. Méthode générale pour la résolution des systemes d’équations simultanées. Comp. Rend. Sci. Paris, 25, 536-538.

Charwand, M., Ahmadi, A., Heidari, A. R. \& Nezhad, A. E. 2015a. Benders decomposition and normal boundary intersection method for multiobjective decision making framework for an electricity retailer in energy markets. IEEE Systems Journal, 9, 1475-1484.

Charwand, M., Ahmadi, A., Siano, P., Dargahi, V. \& Sarno, D. 2015b. Exploring the trade-off between competing objectives for electricity energy retailers through a novel multi-objective framework. Energy Conversion and Management, 91, 12-18.

Chaturvedi, K. T., Pandit, M. \& Srivastava, L. 2009. Particle swarm optimization with time varying acceleration coefficients for non-convex economic power dispatch. International Journal of Electrical Power \& Energy Systems, 31, 249-257.

Chen, P.-H. \& Chang, H.-C. 1995. Large-scale economic dispatch by genetic algorithm. IEEE transactions on power systems, 10, 1919-1926.

Chiang, C.-L. 2005. Improved genetic algorithm for power economic dispatch of units with valve-point effects and multiple fuels. IEEE transactions on power systems, 20, 1690-1699. 
Chiang, C. L. 2016. An Optimal Economic Dispatch Algorithm for Large Scale Power Systems with Cogeneration Units. European Journal of Engineering Research and Science, 1, 10-16.

Chiou, J.-P. 2007. Variable scaling hybrid differential evolution for large-scale economic dispatch problems. Electric Power Systems Research, 77, 212-218.

Chung, C., Liang, C., Wong, K. \& Duan, X. 2010. Hybrid algorithm of differential evolution and evolutionary programming for optimal reactive power flow. IET generation, transmission \& distribution, 4, 84-94.

Clarke, F. H., Ledyaev, Y. S., Stern, R. J. \& Wolenski, P. R. 2008. Nonsmooth analysis and control theory, Springer Science \& Business Media.

Couldry, N. \& Turow, J. 2014. Advertising, big data and the clearance of the public realm: Marketers' new approaches to the content subsidy. International Journal of Communication, 8, 1710-1726.

Cukier, K. 2010. Data, data everywhere: A special report on managing information, Economist Newspaper.

Das, D. B. \& Patvardhan, C. 1998. New multi-objective stochastic search technique for economic load dispatch. IEE Proceedings-Generation, Transmission and Distribution, 145, 747752.

Das, D. B. \& Patvardhan, C. 2002. Reactive power dispatch with a hybrid stochastic search technique. International journal of electrical power \& energy systems, 24, 731-736.

De Stefano, D., Giordano, G. \& Vitale, M. P. 2011. Issues in the analysis of co-authorship networks. Quality \& Quantity, 45, 1091-1107.

Dotta, D., E Silva, A. S. \& Decker, I. C. Design of power system controllers by nonsmooth, nonconvex optimization. Power \& Energy Society General Meeting, 2009. PES'09. IEEE, 2009. IEEE, $1-7$.

E Silva, M. D. A. C., Klein, C. E., Mariani, V. C. \& Dos Santos Coelho, L. 2014. Multiobjective scatter search approach with new combination scheme applied to solve environmental/economic dispatch problem. Energy, 53, 14-21.

Emrouznejad, A. \& Marra, M. 2016. Big Data: Who, What and Where? Social, Cognitive and Journals Map of Big Data Publications with Focus on Optimization. Big Data Optimization: Recent Developments and Challenges. Springer.

Esmaeel Nezhad, A., Ahmadi, A., Javadi, M. S. \& Janghorbani, M. 2015. Multi-objective decision-making framework for an electricity retailer in energy markets using lexicographic 
optimization and augmented epsilon-constraint. International Transactions on Electrical Energy Systems, 25, 3660-3680.

Esmaeily, A., Ahmadi, A., Raeisi, F., Ahmadi, M. R., Nezhad, A. E. \& Janghorbani, M. 2017. Evaluating the effectiveness of mixed-integer linear programming for day-ahead hydro-thermal self-scheduling considering price uncertainty and forced outage rate. Energy, 122, 182-194.

Fetanat, A. \& Shafipour, G. 2011. Generation maintenance scheduling in power systems using ant colony optimization for continuous domains based 0-1 integer programming. Expert Systems with Applications, 38, 9729-9735.

Francis, M. 2012. Future telescope array drives development of exabyte processing. Ars Technica.

Fukuta, N. \& Ito, T. Toward combinatorial auction-based better electric power allocation on sustainable electric power systems. Commerce and Enterprise Computing (CEC), 2011 IEEE 13th Conference on, 2011. IEEE, 392-399.

Gerbex, S., Cherkaoui, R. \& Germond, A. J. 2001. Optimal location of multi-type FACTS devices in a power system by means of genetic algorithms. IEEE transactions on power systems, $16,537-544$.

Ghadikolaei, H. M., Ahmadi, A., Aghaei, J. \& Najafi, M. 2012. Risk constrained self-scheduling of hydro/wind units for short term electricity markets considering intermittency and uncertainty. Renewable and Sustainable Energy Reviews, 16, 4734-4744.

Gong, M., Cai, Q., Ma, L. \& Jiao, L. 2016. Big Network Analytics Based on Nonconvex Optimization. Big Data Optimization: Recent Developments and Challenges. Springer.

Goyena, S. G., Sádaba, Ó. A. \& Acciona, S. Sizing and analysis of big scale and isolated electric systems based on renewable sources with energy storage. Sustainable Alternative Energy (SAE), 2009 IEEE PES/IAS Conference on, 2009. IEEE, 1-7.

Grossmann, I. E. 2014. Global Optimization in engineering design, Springer Science \& Business Media.

Guide, L. 2014. English Version: A Collection of Facts and Figures about the Large Hadron Collider (LHC) in the form of Questions and Answers, CERN-Brochure-2009-003-Eng. CERN. English version.

Gunasekaran, A., Papadopoulos, T., Dubey, R., Wamba, S. F., Childe, S. J., Hazen, B. \& Akter, S. 2017. Big data and predictive analytics for supply chain and organizational performance. Journal of Business Research, 70, 308-317. 
Guo, J., Hug, G. \& Tonguz, O. K. 2016. A Case for Non-Convex Distributed Optimization in Large-Scale Power Systems. IEEE Transactions on Power Systems.

Habibi, M., Rashidinejad, M., Zeinaddini-Meymand, M. \& Fadainejad, R. 2014. An efficient scatter search algorithm to solve transmission expansion planning problem using a new load shedding index. International Transactions on Electrical Energy Systems, 24, 153-165.

Hestenes, M. R. \& Stiefel, E. 1952. Methods of conjugate gradients for solving linear systems, NBS.

Hoos, H. H. 1998. Stochastic local search-methods, models, applications, Ios Press.

Hoos, H. H. \& Stützle, T. 2004. Stochastic local search: Foundations and applications, Elsevier.

Hou, Y.-H., Wu, Y.-W., Lu, L.-J. \& Xiong, X.-Y. Generalized ant colony optimization for economic dispatch of power systems. Power System Technology, 2002. Proceedings. PowerCon 2002. International Conference on, 2002. IEEE, 225-229.

Hou, Y.-H., Xiong, X.-Y., Wu, Y.-W. \& Lu, L.-J. 2004. Economic dispatch of power systems based on generalized ant colony optimization method [J]. Proceedings of the Csee, 3, 014.

Huser, V. \& Cimino, J. J. 2016. Impending challenges for the use of Big Data. International Journal of Radiation Oncology• Biology• Physics, 95, 890-894.

Jiang, H., Wang, K., Wang, Y., Gao, M. \& Zhang, Y. 2016. Energy big data: A survey. IEEE Access, 4, 3844-3861.

Johnson, R. 2010. Scaling facebook to 500 million users and beyond. Retrieved May, 4, 2014.

Kache, F., Kache, F., Seuring, S. \& Seuring, S. 2017. Challenges and opportunities of digital information at the intersection of Big Data Analytics and supply chain management. International Journal of Operations \& Production Management, 37, 10-36.

Kaldellis, J. 2002. Optimum autonomous wind-power system sizing for remote consumers, using long-term wind speed data. Applied Energy, 71, 215-234.

Karami, M., Shayanfar, H., Aghaei, J. \& Ahmadi, A. 2014. Scenario-based security-constrained hydrothermal coordination with volatile wind power generation. Renewable and Sustainable Energy Reviews, 28, 726-737.

Karmitsa, N. 2016. Numerical Methods for Large-Scale Nonsmooth Optimization. Big Data Optimization: Recent Developments and Challenges. Springer. 
Katsigiannis, Y., Kanellos, F. \& Papaefthimiou, S. 2016. A software tool for capacity optimization of hybrid power systems including renewable energy technologies based on a hybrid genetic algorithm—-tabu search optimization methodology. Energy Systems, 7, 33-48.

Kaur, R., Krishnasamy, V., Muthusamy, K. \& Chinnamuthan, P. 2017. A novel proton exchange membrane fuel cell based power conversion system for telecom supply with genetic algorithm assisted intelligent interfacing converter. Energy Conversion and Management, 136, 173-184.

Khatod, D. K., Pant, V. \& Sharma, J. 2014. Evolutionary programming based optimal placement of renewable distributed generators. IEEE Transactions on Power Systems, 28, 683-695.

Kung, L. \& Wang, H.-F. A recommender system for the optimal combination of energy resources with cost-benefit analysis. Industrial Engineering and Operations Management (IEOM), 2015 International Conference on, 2015. IEEE, 1-10.

Lai, L. L. 1998. Intelligent system applications in power engineering: evolutionary programming and neural networks, John Wiley \& Sons, Inc.

Lakshminarasimman, L. \& Subramanian, S. 2006. Short-term scheduling of hydrothermal power system with cascaded reservoirs by using modified differential evolution. IEE ProceedingsGeneration, Transmission and Distribution, 153, 693-700.

Laney, D. 2001. 3D data management: Controlling data volume, velocity and variety. META Group Research Note, 6, 70.

Layton, J. 2014. Amazon Technology.

Lee, C.-H. \& Wu, C.-H. 2015. A Novel Big Data Modeling Method for Improving Driving Range Estimation of EVs. IEEE Access, 3, 1980-1994.

Lee, J.-D., Baek, C., Kim, H.-S. \& Lee, J.-S. 2014a. Development pattern of the DEA research field: a social network analysis approach. Journal of Productivity Analysis, 41, 175-186.

Lee, J., Bagheri, B. \& Kao, H.-A. 2015. A cyber-physical systems architecture for industry 4.0based manufacturing systems. Manufacturing Letters, 3, 18-24.

Lee, J., Wu, F., Zhao, W., Ghaffari, M., Liao, L. \& Siegel, D. 2014b. Prognostics and health management design for rotary machinery systems—-Reviews, methodology and applications. Mechanical systems and signal processing, 42, 314-334.

Lee, K. Y. \& Yang, F. F. 1998. Optimal reactive power planning using evolutionary algorithms: A comparative study for evolutionary programming, evolutionary strategy, genetic algorithm, and linear programming. IEEE Transactions on power systems, 13, 101-108. 
Li, J., Tao, F., Cheng, Y. \& Zhao, L. 2015. Big data in product lifecycle management. The International Journal of Advanced Manufacturing Technology, 81, 667-684.

Liang, C., Chung, C., Wong, K. \& Duan, X. 2007. Parallel optimal reactive power flow based on cooperative co-evolutionary differential evolution and power system decomposition. IEEE transactions on power systems, 22, 249-257.

Lin, S., Liu, M., Li, Q., Lu, W., Yan, Y. \& Liu, C. 2017. Normalised normal constraint algorithm applied to multi-objective security-constrained optimal generation dispatch of large-scale power systems with wind farms and pumped-storage hydroelectric stations. IET Generation, Transmission \& Distribution.

Lin, W.-M., Cheng, F.-S. \& Tsay, M.-T. 2002. An improved tabu search for economic dispatch with multiple minima. IEEE Transactions on power systems, 17, 108-112.

Liu, D. \& Cai, Y. 2005. Taguchi method for solving the economic dispatch problem with nonsmooth cost functions. IEEE transactions on power systems, 20, 2006-2014.

Liu, Z., Wierman, A., Chen, Y., Razon, B. \& Chen, N. 2014. Data center demand response: Avoiding the coincident peak via workload shifting and local generation. Performance Evaluation, 70, 770-791.

Lyden, S. \& Haque, M. E. 2016. A simulated annealing global maximum power point tracking approach for PV modules under partial shading conditions. IEEE Transactions on Power Electronics, 31, 4171-4181.

Macgillivray, A., Jeffrey, H., Winskel, M. \& Bryden, I. 2014. Innovation and cost reduction for marine renewable energy: A learning investment sensitivity analysis. Technological Forecasting and Social Change, 87, 108-124.

Manyika, J., Chui, M., Brown, B., Bughin, J., Dobbs, R., Roxburgh, C. \& Byers, A. H. 2011. Big data: The next frontier for innovation, competition, and productivity.

Mavalizadeh, H. \& Ahmadi, A. 2014. Hybrid expansion planning considering security and emission by augmented epsilon-constraint method. International Journal of Electrical Power \& Energy Systems, 61, 90-100.

Mezger, A. J. \& De Almeida, K. C. 2007. Short term hydrothermal scheduling with bilateral transactions via bundle method. International Journal of Electrical Power \& Energy Systems, 29, 387-396.

Midlam-Mohler, S., Ewing, S., Marano, V., Guezennec, Y. \& Rizzoni, G. PHEV fleet data collection and analysis. Vehicle Power and Propulsion Conference, 2009. VPPC'09. IEEE, 2009. IEEE, 1205-1210. 
Mirkes, E., Coats, T. J., Levesley, J. \& Gorban, A. 2016. Handling missing data in large healthcare dataset: A case study of unknown trauma outcomes. Computers in biology and medicine, 75, 203-216.

Mistakidis, E. S. \& Stavroulakis, G. E. 2014. Nonconvex optimization in mechanics: algorithms, heuristics and engineering applications by the FEM, Springer Science \& Business Media.

Mizutani, A., Yukawa, T., Numa, K., Kuze, Y., Iizaka, T., Yamagishi, T., Matsui, T. \& Fukuyama, Y. 2005. Improvement of input-output correlations of electric power load forecasting by scatter search. Intelligent Systems Application to Power Systems, 2005. Proceedings of the 13th International Conference on, IEEE, 5 pp.

Moghimi, H., Ahmadi, A., Aghaei, J. \& Rabiee, A. 2014. Stochastic techno-economic operation of power systems in the presence of distributed energy resources. International Journal of Electrical Power \& Energy Systems, 45, 477-488.

Mori, H. \& Goto, Y. A parallel tabu search based method for determining optimal allocation of FACTS in power systems. Power System Technology, 2000. Proceedings. PowerCon 2000. International Conference on, 2000. IEEE, 1077-1082.

Mori, H. \& Shimomugi, K. Transmission network expansion planning with Scatter Search. Systems, Man and Cybernetics, 2007. ISIC. IEEE International Conference on, 2007. IEEE, 3749-3754.

Murdoch, T. B. \& Detsky, A. S. 2014. The inevitable application of big data to health care. Jama, 309, 1351-1352.

Naderi, E., Narimani, H., Fathi, M. \& Narimani, M. R. 2017. A Novel Fuzzy Adaptive Configuration of Particle Swarm Optimization to Solve Large-Scale Optimal Reactive Power Dispatch. Applied Soft Computing.

Newton, M. H., Pham, D. N., Tan, W. L., Portmann, M. \& Sattar, A. Stochastic local search based channel assignment in wireless mesh networks. International Conference on Principles and Practice of Constraint Programming, 2014. Springer, 832-847.

Niknam, T. 2010. A new fuzzy adaptive hybrid particle swarm optimization algorithm for nonlinear, non-smooth and non-convex economic dispatch problem. Applied Energy, 87, 327-339.

Niu, D., Wang, Y. \& Wu, D. D. 2010. Power load forecasting using support vector machine and ant colony optimization. Expert Systems with Applications, 37, 2531-2539.

O’donoghue, J. \& Herbert, J. 2012. Data management within mHealth environments: Patient sensors, mobile devices, and databases. Journal of Data and Information Quality (JDIQ), 4, 5. 
Outrata, J., Kocvara, M. \& Zowe, J. 2014. Nonsmooth approach to optimization problems with equilibrium constraints: theory, applications and numerical results, Springer Science \& Business Media.

Pan, I. \& Das, S. 2016. Fractional order fuzzy control of hybrid power system with renewable generation using chaotic PSO. ISA transactions, 62, 19-29.

Panda, S. \& Yegireddy, N. K. 2014. Automatic generation control of multi-area power system using multi-objective non-dominated sorting genetic algorithm-II. International Journal of Electrical Power \& Energy Systems, 53, 54-64.

Papadopoulos, T., Gunasekaran, A., Dubey, R., Altay, N., Childe, S. J. \& Fosso-Wamba, S. 2017. The role of Big Data in explaining disaster resilience in supply chains for sustainability. Journal of Cleaner Production, 142, 1108-1118.

Park, J.-B., Lee, K.-S., Shin, J.-R. \& Lee, K. Y. 2005. A particle swarm optimization for economic dispatch with nonsmooth cost functions. IEEE Transactions on Power systems, 20, 3442.

Park, J.-B., Lee, K.-S., Shin, J.-R. \& Lee, Y. Economic load dispatch for nonsmooth cost functions using particle swarm optimization. Power Engineering Society General Meeting, 2003, IEEE, 2004. IEEE, 938-944.

Paro, A. \& Fadigas, E. A methodology for biomass cogeneration plants overall energy efficiency calculation and measurement-A basis for generators real time efficiency data disclosure. Power Systems Conference and Exposition (PSCE), 2011 IEEE/PES, 2011. IEEE, 1-7.

Picciano, A. G. 2012. The Evolution of Big Data and Learning Analytics in American Higher Education. Journal of Asynchronous Learning Networks, 16, 9-20.

Pothiya, S., Ngamroo, I. \& Kongprawechnon, W. 2010. Ant colony optimisation for economic dispatch problem with non-smooth cost functions. International Journal of Electrical Power \& Energy Systems, 32, 478-487.

Rahimi-Eichi, H., Jeon, P. B., Chow, M.-Y. \& Yeo, T.-J. Incorporating big data analysis in speed profile classification for range estimation. Industrial Informatics (INDIN), 2015 IEEE 13th International Conference on, 2015. IEEE, 1290-1295.

Rajendran, P., Jeyshankar, R. \& Elango, B. 2011. Scientometric analysis of contributions to Journal of Scientific and Industrial Research. International Journal of Digital Library Services, 1, 79-89.

Rajesh, K., Bhuvanesh, A., Kannan, S. \& Thangaraj, C. 2016. Least cost generation expansion planning with solar power plant using Differential Evolution algorithm. Renewable Energy, 85, 677-686. 
Ramírez-Rosado, I. J. \& Domínguez-Navarro, J. A. 2006. New multiobjective tabu search algorithm for fuzzy optimal planning of power distribution systems. IEEE Transactions on Power systems, 21, 224-234.

Romero, R., Gallego, R. \& Monticelli, A. Transmission system expansion planning by simulated annealing. Power Industry Computer Application Conference, 1995. Conference Proceedings., 1995 IEEE, 1995. IEEE, 278-284.

Rotolo, D., Rafols, I., Hopkins, M. M. \& Leydesdorff, L. 2014. Scientometric Mapping as a Strategic Intelligence Tool for the Governance of Emerging Technologies.

Rouhi, F. \& Effatnejad, R. 2015. Unit commitment in power system t by combination of Dynamic Programming (DP), Genetic Algorithm (GA) and Particle Swarm Optimization (PSO). Indian Journal of Science and Technology, 8, 134.

Roy, P., Ghoshal, S. \& Thakur, S. 2010. Biogeography based optimization for multi-constraint optimal power flow with emission and non-smooth cost function. Expert Systems with Applications, 37, 8221-8228.

Sayah, S. \& Zehar, K. 2008. Modified differential evolution algorithm for optimal power flow with non-smooth cost functions. Energy conversion and Management, 49, 3036-3042.

Schmidt, G. \& Wilhelm, W. E. 2000. Strategic, tactical and operational decisions in multinational logistics networks: a review and discussion of modelling issues. International Journal of Production Research, 38, 1501-1524.

Selvakumar, A. I. \& Thanushkodi, K. 2007. A new particle swarm optimization solution to nonconvex economic dispatch problems. IEEE transactions on power systems, 22, 42-51.

Shaheen, H. I., Rashed, G. I. \& Cheng, S. 2011. Optimal location and parameter setting of UPFC for enhancing power system security based on differential evolution algorithm. International Journal of Electrical Power \& Energy Systems, 33, 94-105.

Sharafi Masouleh, M., Salehi, F., Raeisi, F., Saleh, M., Brahman, A. \& Ahmadi, A. 2016. Mixedinteger programming of stochastic hydro self-scheduling problem in joint energy and reserves markets. Electric Power Components and Systems, 44, 752-762.

Sheu, J.-B. 2008. Green supply chain management, reverse logistics and nuclear power generation. Transportation Research Part E: Logistics and Transportation Review, 44, 19-46.

Shor, P. W. Algorithms for quantum computation: Discrete logarithms and factoring. Foundations of Computer Science, 1994 Proceedings., 35th Annual Symposium on, 1994. Ieee, 124-134. 
Smith, M., Szongott, C., Henne, B. \& Von Voigt, G. Big data privacy issues in public social media. Digital Ecosystems Technologies (DEST), 2012 6th IEEE International Conference on, 2012. IEEE, 1-6.

Soares, J., Borges, N., Canizes, B. \& Vale, Z. Probabilistic estimation of the state of electric vehicles for smart grid applications in big data context. Power \& Energy Society General Meeting, 2015 IEEE, 2015. IEEE, 1-5.

Su, C.-T. \& Lee, C.-S. 2004. Network reconfiguration of distribution systems using improved mixed-integer hybrid differential evolution. IEEE Transactions on Power Delivery, 18, 10221027.

Su, W. \& Chow, M.-Y. 2012. Performance evaluation of an EDA-based large-scale plug-in hybrid electric vehicle charging algorithm. IEEE Transactions on Smart Grid, 3, 308-315.

Sullivan, D. 2015. Google still doing at least 1 trillion searches per year. Retrieved March, 13, 2015.

Sun, W. \& Yuan, Y.-X. 2006. Optimization theory and methods: nonlinear programming, Springer Science \& Business Media.

Surendra, U. \& Parthasarathy, S. 2014. Optimal Location of Series FACTS Device Using PSO Technique to Reduce the Losses and to Enhance Power Transfer Capability in a Power System. Emerging Research in Electronics, Computer Science and Technology. Springer.

Swan, M. 2014. The quantified self: Fundamental disruption in big data science and biological discovery. Big Data, 1, 85-99.

Syahputra, R. \& Soesanti, I. Power System Stabilizer model based on Fuzzy-PSO for improving power system stability. Advanced Mechatronics, Intelligent Manufacture, and Industrial Automation (ICAMIMIA), 2015 International Conference on, 2015. IEEE, 121-126.

Tay, L. 2010. Inside eBay’s 90PB data warehouse.

Tsai, M.-S. \& Hsu, F.-Y. 2010. Application of grey correlation analysis in evolutionary programming for distribution system feeder reconfiguration. IEEE Transactions on Power Systems, 25, 1126-1134.

Walters, D. C. \& Sheble, G. B. 1994. Genetic algorithm solution of economic dispatch with valve point loading. IEEE transactions on Power Systems, 8, 1325-1332.

Wang, S.-K., Chiou, J.-P. \& Liu, C.-W. 2009. Parameters tuning of power system stabilizers using improved ant direction hybrid differential evolution. International Journal of Electrical Power \& Energy Systems, 31, 34-42. 
Wang, Y., Li, B. \& Weise, T. 2010. Estimation of distribution and differential evolution cooperation for large scale economic load dispatch optimization of power systems. Information Sciences, 180, 2405-2420.

Watkins, D. S. 2004. Fundamentals of matrix computations, John Wiley \& Sons.

West, D. M. 2012. Big data for education: Data mining, data analytics, and web dashboards. Governance Studies at Brookings, 4, 1-0.

Wood, R. J., Bahaj, A. S., Turnock, S. R., Wang, L. \& Evans, M. 2010. Tribological design constraints of marine renewable energy systems. Philosophical Transactions of the Royal Society of London A: Mathematical, Physical and Engineering Sciences, 368, 4807-4827.

Wu, K.-J., Liao, C.-J., Tseng, M.-L., Lim, M. K., Hu, J. \& Tan, K. 2017. Toward sustainability: using big data to explore the decisive attributes of supply chain risks and uncertainties. Journal of Cleaner Production, 142, 663-676.

Wu, Q., Nielsen, A. H., Ostergaard, J., Cha, S. T., Marra, F., Chen, Y. \& Træholt, C. Driving pattern analysis for electric vehicle (EV) grid integration study. Innovative Smart Grid Technologies Conference Europe (ISGT Europe), 2010 IEEE PES, 2010. IEEE, 1-6.

Wu, Q. H. \& Ma, J. 1995. Power system optimal reactive power dispatch using evolutionary programming. IEEE Transactions on power systems, 10, 1243-1249.

Xu, Z., Liu, Y., Yen, N., Mei, L., Luo, X., Wei, X. \& Hu, C. 2016. Crowdsourcing based description of urban emergency events using social media big data. IEEE Transactions on Cloud Computing.

Yan, W., Lu, S. \& Yu, D. C. 2004. A novel optimal reactive power dispatch method based on an improved hybrid evolutionary programming technique. IEEE transactions on Power systems, 19, 913-918.

Yang, H.-T., Yang, P.-C. \& Huang, C.-L. 1996. Evolutionary programming based economic dispatch for units with non-smooth fuel cost functions. IEEE transactions on Power Systems, 11, 112-118.

Yuryevich, J. \& Wong, K. P. 1999. Evolutionary programming based optimal power flow algorithm. IEEE transactions on Power Systems, 14, 1245-1250.

Zhang, D., Luh, P. B. \& Zhang, Y. 1999. A bundle method for hydrothermal scheduling. IEEE Transactions on power systems, 14, 1355-1361.

Zhang, L., Chen, Y., Zhu, J., Pan, M., Sun, Z. \& Wang, W. Data quality analysis and improved strategy research on operations management system for electric vehicles. Electric Utility 
Deregulation and Restructuring and Power Technologies (DRPT), 2015 5th International Conference on, 2015. IEEE, 2715-2720.

Zhao, R., Liu, Y., Zhang, N. \& Huang, T. 2017. An optimization model for green supply chain management by using a big data analytic approach. Journal of Cleaner Production, 142, 10851097.

Zhu, J. 2015. Optimization of power system operation, John Wiley \& Sons.

Zhuang, F. \& Galiana, F. 1990. Unit commitment by simulated annealing. IEEE Transactions on Power Systems, 5, 311-318.

Zicari, R. V., Rosselli, M., Ivanov, T., Korfiatis, N., Tolle, K., Niemann, R. \& Reichenbach, C. 2016. Setting Up a Big Data Project: Challenges, Opportunities, Technologies and Optimization. Big Data Optimization: Recent Developments and Challenges. Springer.

Zikopoulos, P. \& Eaton, C. 2011. Understanding big data: Analytics for enterprise class hadoop and streaming data, McGraw-Hill Osborne Media. 